\title{
Contribution to the Collaborative Work in Virtual Organization - a Case Study
}

\author{
Fernando A. Crespo ${ }^{1}$, Chandra Sekhar Pedamallư ${ }^{2,3}$, Linet Özdamar ${ }^{4}$, Gerhard Wilhelm Weber ${ }^{5}$
}

\author{
1Universidad de Valparaíso, Brigadier de la Cruz 1050, Santiago, Chile, facrespo@gmail.com \\ 2 Department of Medical Oncology, Dana-Farber Cancer Institute, 450 Brookline Avenue, 02215 Boston, MA, USA. \\ ${ }^{3}$ The Broad Institute of MIT and Harvard, Cambridge, MA, USA, pcs.murali@gmail.com \\ ${ }^{4}$ Yeditepe University, Industrial and Systems Engineering, 26 Ağustos Yerleșimi \\ Kayıșdağı Cad., 34755 Kayıșdağı, Istanbul, Turkey, ozdamar.linet@gmail.com
${ }^{5}$ Institute of Applied Mathematics (UME), Middle East Technical University (ODTÜ), 06531 Ankara, Turkey, \\ gweber@metu.edu.tr
}

\begin{abstract}
A virtual organization is a community of people who interact together socially on a technical platform. These kinds of communities are built on a common interest, a common problem or a common task of its members that is pursued on the basis of implicit and explicit codes of behavior. The six dimensions that are normally used to analyze virtual organizations are the use of technologies, sense of belonging, success factors, level of trust from members, virtual community management, and contents of the virtual community. The virtual organizations defined in the literature are not defined separately for non-profit research virtual organization. Here we present analysis of non-profit research virtual organization, European Working Group on Operational Research for Development (EGW ORD). This paper provides a summary of achievements and challenges faced in building a virtual organization. This kind of analysis plays a vital role in establishing new non-profit virtual organizations to serve the research community in their field of interest. It is also helpful to the group in broadening its presence and involving more researchers, practitioners and students in the field of operational research.
\end{abstract}

Keywords: Virtual organization, Virtual community, Operational Research, Societies, EURO.

\section{Introduction}

Virtual organizations are defined as a community of people who interact together socially on a technical platform. The community is mainly built on a common interest / common problem / common task that are pursued on the basis of implicit and explicit codes of behavior. In 1993, Howard Rheingold coined this word in his book on virtual community and virtual organization. The technical platform which is the basis for virtual organization / community enables and supports the members of the community through interactions and helps to build trust and common areas of interest among the members (Leimeister et al., 2006). It also helps the members to collaborate, maintain and sustain member relationships in distributed work environment through various modern communications media that are geographically dispersed (LunaReyes et al., 2008, Zurada 2009). In recent years, there are several virtual organizations started over the internet. One such successful and popular virtual organization is Facebook, LinkedIn, Twitter, and so on. In order to establish a virtual organization, there is need for a community of people with a common interest having the ability of using cyber infrastructure. Virtual organization and virtual communities are interchangeably used in the literature and in this paper.

In the last decade, there are several researchers who study the internet phenomenon on virtual communities in order to understand virtual organizations and communities (for example: Leimeister et al., 2006). At the starting phase of each virtual community, the organizers or initiators need to get an idea on the value added to the people involved in the virtual community. This will be one of the stepping stones for the success of virtual community / organizations. Rodgers and Chen (2005) study the impact of virtual organizations initiated by women suffering from breast cancer in terms of psychosocial benefits such as experience sharing, societal support for patients, discussion blogs, and so on.

Yuan et al., (2000) explores the concept of virtuality as a nature of organizations and proposes a framework containing six critical dimensions, which may be used as a basis to characterize, study and compare virtual organizations. These critical dimensions are purpose, connectivity, technology, boundary, business process and people. This paper contributes

Received: $24^{\text {th }}$ February 2012; revised $6^{\text {th }}$ April 2012; accepted $3^{\text {rd }}$ July 2012 
to the conceptual discussion of virtual organizations and provides some important insights useful in the design of virtual organizations and the transformation of traditional organizations into virtual organizations. There are several research studies that are concerned with the six dimensions that are used to analyze a virtual community / virtual organization. These are the use of technologies (Wamalwa 2007, Kljajić Borštnar, 2012), sense of belonging (Blanchard and Markus, 2002), success factors (Leimeister, et al., 2006), level of trust among members (Abdul-Rahman and Hailes 2000, Leimeister and Krcmar 2005), virtual community management (Jansson et al., 2007), and contents of the virtual community (not well studied).

Moreover, most of the implementations of virtual organization in the literature are not focused non-profit research organization. This is one of the first studies that presents a case study that indicates the achievements and challenges faced in establishing nonprofit research virtual organizations. The case study presented in this is the experiences and achievements of the European Working Group on Operational Research for Development (EWG ORD) as a virtual organization in terms of the six dimensions mentioned above. Furthermore, the challenges met by EWG ORD are discussed. This study may enlighten researchers who wish to establish new virtual organizations in their field of research interest.

\section{Virtual organizations / Virtual communities}

Zurada (2009) presents some common characteristics of virtual community and virtual organization as shown below. Virtual community and virtual organization are

- Distributed across space, with participants spanning localities and institutions,

- Distributed across time, allowing synchronous as well asynchronous interactions,

- Dynamic structures and processes, at every stage of the organizational lifecycle,

- Computationally enabled, via collaboration support systems including e-mail, teleconferencing, telepresence, awareness, social computing, and group information management tools, and

- Computationally enhanced, with simulations, databases, instrumentation, analytic tools and services which facilitate interaction with humans that are integral to the functioning of the organization.

Figure 1 illustrates a paradigm of six dimensions that are required for analysis of a virtual organization. The six dimensions includes use of technologies, sense of belonging, success factors, level of trust from members, virtual community management, and contents of the virtual community.

Most of the studies that are presented in the literature are not very well studied in the context of nonprofit virtual organizations is content. So, the following section tries to illustrate all the dimensions used to analyze the nonprofit research virtual organization. The success in this type of organization mainly depends on the factors such as contents of the organi-

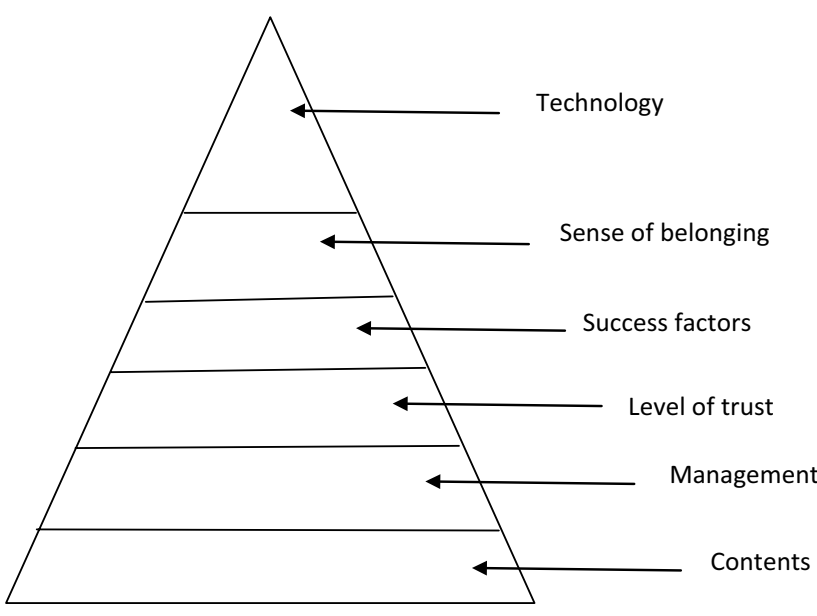

Figure 1: Six dimensions required for analysis of a virtual organization.

zation which is not well studied in the literature. Therefore, we attempt to summarize it with a case study.

\section{Case Study: EWG ORD: European working group on operational research for development}

\section{Brief history:}

EURO, the Association of European Operational Research Societies, is a "non profit" association domiciled in Switzerland. Its affairs are regulated by a Council consisting of representatives of all its members and an Executive Committee which constitutes its board of directors. Its aim is to promote Operational Research throughout Europe. EWG ORD, a working group of EURO, is a creative idea that has evolved during informal conversations between fellow researchers and doctoral students at the EURO Summer Institute (ESIXXII, 2004). One of the main motivations behind starting this group is leverage the research and educational opportunities for research students, researchers, and practitioners from developing countries. One of the other driving forces in founding this working group is to lead the way to systematically analyze the data from projects developed in developing countries, to exchange ideas between researchers working on various projects meant for developing the status of various countries below poverty line. However, this working group is not limited to individuals from developing countries. The first and foremost thing which everybody in founding members of the working group agreed up on is to maintain regular and organized communication among members. This regular communication will help to configure research ideas and highlight topics of interest that need immediate attention.

In the following months, members of the founding team started interacting with potential members for the working group through emails and presentations with the aim of submitting a proposal to EURO. These efforts lead to the formation of the working group, EWG ORD. 


\section{Aim of the EWG ORD:}

The aim and objectives of the working group are listed below (http://web.ing.puc.cl/ fcrespo/eurofdv/):

- to disseminate state-of-the-art knowledge and to support research in operational research for development,

- to assist in gathering the operational research for development communities in Europe organized under the umbrella of EURO,

- to support preparation, refereeing and editing of publications,

- to establish regular information channels and regular meetings,

- to involve industrial organizations and users of optimization in the activities listed above,

- to achieve vivid exchange between scientific experience and enthusiasm of the youth,

- to promote education, qualification and democratic participation in decision making at all levels,

- to promote collaborative learning,

- to encourage building up a common and developing Europe, and

- to establish peace and friendship in Europe and in the world.

\section{Members of EWG ORD:}

EWG ORD has 155 registered members from 37 different countries and a presence in five different continents. Figure 2 illustrates the composition of the members indicating the success of the working group in reaching the researchers across the globe.

\section{Presence in Continent}

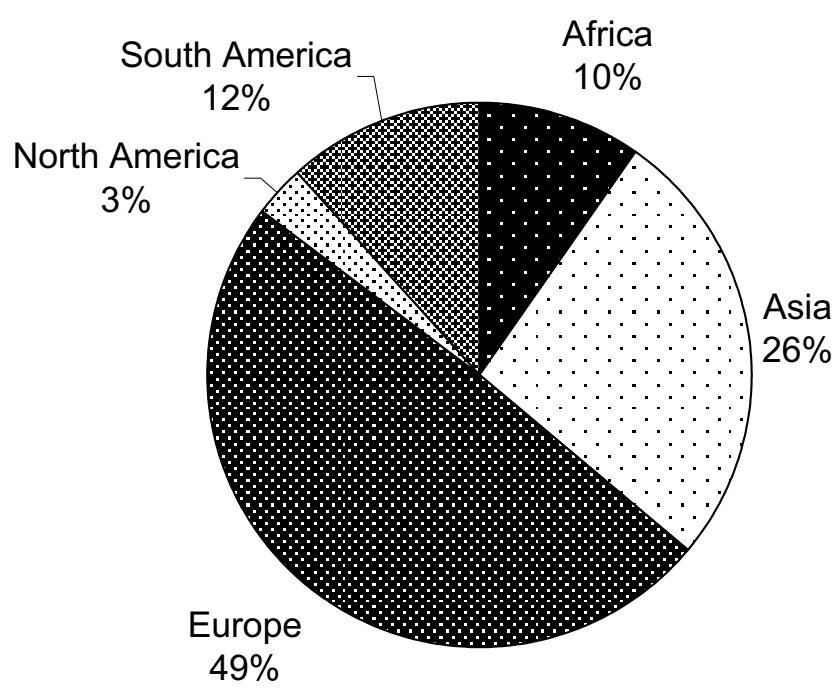

Figure 2: Member distribution across different continents.

The group's member composition also confirms the motivation of researchers both from the developed and the developing nations in the concept of Operational Research applications.

\section{EWG ORD: A virtual organization}

In this section, a list the achievements and challenges in terms of the six dimensions of virtual organizations that help the EWG ORD increase its influence and broaden developments.

\subsection{Use of technology}

After the proposal of the EWG ORD group, the first important step for using technology (Wamalwa 2007) was to build a website that would enable the cohesion and the permanent diffusion of the group's activities (EWG ORD 2010). The format of this website is similar to other established working groups from EURO (EURO 2010). The goal of such similarity is to help users (who are familiar with other working groups) in easy navigation. In fact, most the group members have memberships in other working groups established in EURO. After building the website, emails were sent to potential members from other EURO working groups, to INFORMS members, and other OR societies from developed and developing nations. The main focus of the website is to use open source technologies such as PHP, HTML in order to offset the cost burden. The technology aspects that are not fully integrated are instant messaging facility, Internet relay chat (IRC), bulletin boards, blogs, wikis, collaborative software, social network search engines, social book marking, peer-to-peer, virtual presence (Wamalwa 2007), Skype and messengers (from Gmail or Microsoft Messenger).

Administrative concerns are the cause of these missing tools. The web page is hosted by a university server that is subjected to the university information technology policies. These policies restrict the use of some open source software available over the internet such as IRC messenger and internet blogging, which are used in community sites.

The next step in the technology dimension is to identify the common interests and needs of the members in the working group. One of the main challenges in this step is to gauge the technical expertise of the members in using these technologies. The other challenge is implementing the technologies that allow users to find the researchers with common interests. In fact, this is the main goal of social networks. So, adding interactive technologies to the web site can indeed open up new joint projects.

\subsection{Sense of belonging}

The concept of the sense of belonging to a community is a feeling of the individual's personal connections to a social group that leads to important outcomes in face-to-face organizations and human communities. In work organizations, sense of belonging to a community increases job satisfaction and organizational citizenship behavior, i.e. loyalty, civic virtue, altruism, and courtesy to the organization (Blanchard and Markus, 2002). In the case of EWG ORD, sense of belonging is one of the core objectives which will enable the organization to move forward and build a strong community. Blanchard and Markus (2002) present the four dimensions of sense of belonging to communities that are listed below: 
1. Feelings of membership:

This dimension can be defined as the feelings of belonging to, and identifying with, the community.

2. Feelings of influence:

This is defined as the feelings of having influence on, and being influenced by, the community.

3. Integration and fulfillment of needs:

This is presented as the feelings of being supported by others in the community while also supporting them.

4. Shared emotional connection:

This sense of belonging to the community is defined as the feelings of relationships, shared history, and a "spirit" of community.

These aspects are very difficult to see and measure, as EWG ORD does not have formal information on this dimension. However, sense of belonging can be gauged by the involvement of the member in the working group activities such as attending workshops, conferences, meetings organized by the EWG ORD. In the future, EWG ORD is planning to collect data that may be in the form of naturalistic inquiry (Blanchard and Markus, 2002). This data can be used for understanding community belongingness to EWG ORD group.

One of the primary indicators of the sense of belonging among group members is the number of presentations that are made by the members and the research community in the workshops/conference streams that are organized by EWG ORD. Figure 3 illustrates the annual number of presentations made from the year 2006 onwards.
The other important indicator is sharing important and exciting data in the conferences / workshop organized by EWG ORD. Some interesting exchanges of ideas made during meetings are listed below.

Rosario and Rosario (2010) present two private initiatives in Philippines towards development in education. These initiatives are made on two fronts: a national OR organization working on projects for the government to promote good governance and private foundation efforts at uplifting public school education. Their work also illustrates OR as a tool that can help policy-makers realize the goal of an improved education for the poor.

Cochran (2010) discusses his experiences with Statistics Without Borders (SWB), Operations Research Practice for Africa (OPRA), and INFORMS Transactions on Education (ITE). His talk mainly focuses on SWB's efforts in collecting post earthquake data in Haiti, OPRA's efforts in using OR to address urban transportation and water resource management issues in Africa, and ITE's efforts in building and maintaining a collection of freely accessible of OR cases (with teaching notes) for classroom use by college instructors.

Weber et al., (2010) present as system dynamic approach to study the effects of infrastructure facilities on the quality of primary education. The model is built using the Cross Impact Analysis (CIA) method of relating entities and attributes relevant to the primary education system in any given community. The resulting model enables to predict the effects of infrastructural facilities on the access of primary education by the community so that policy makers take more effective actions in campaigns.

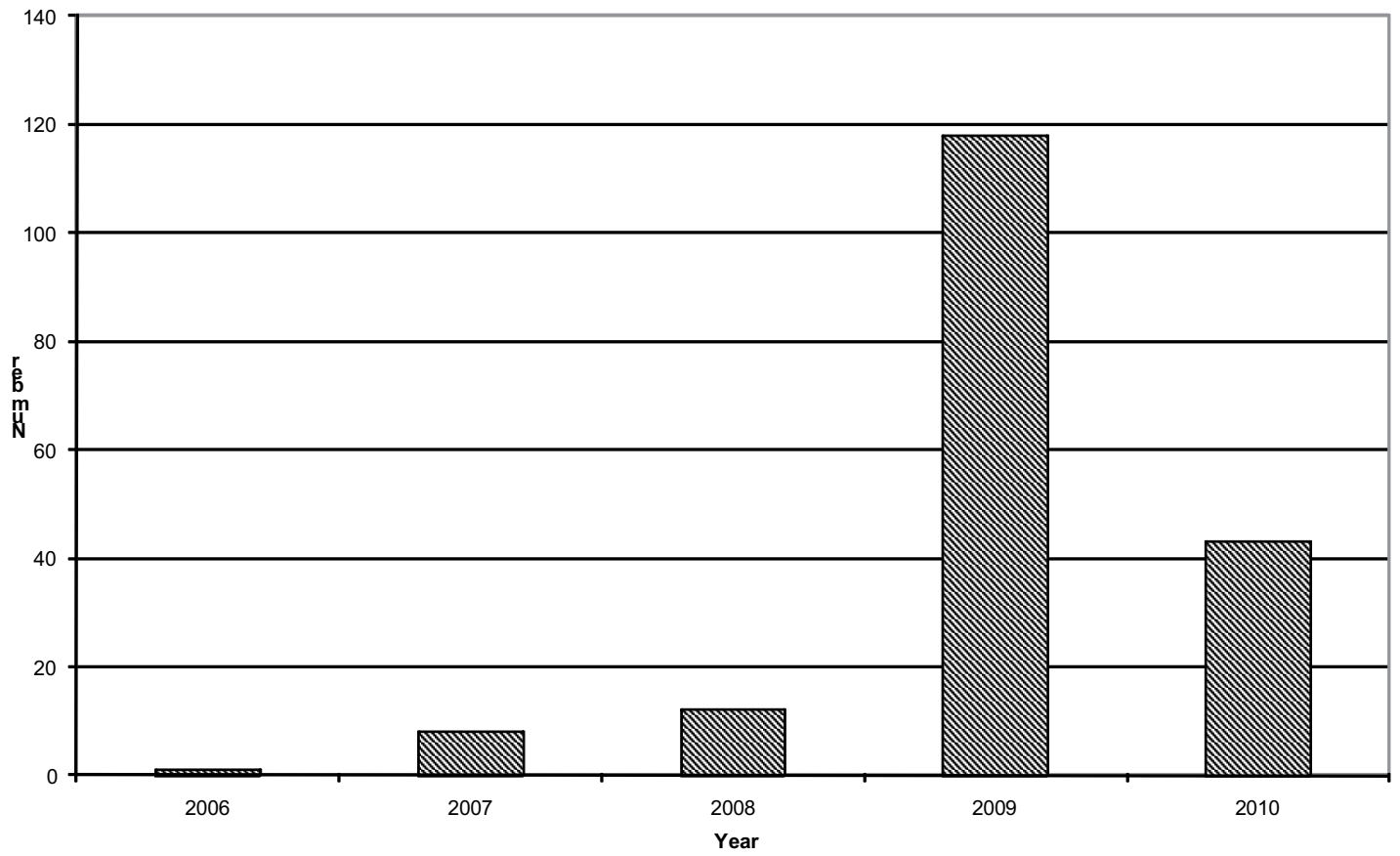

Figure 3: Distribution of total number of presentations made over the years in EWG ORD streams. 
There are several other works presented in these meetings, such as OR applications in urban occupation patterns analysis (Rave, 2010), design of strategic international business centers for suppliers (Bashiri and Mohtajeb, 2010), and so on.

These and similar discussions help to disseminate the state-of-the-art knowledge within and outside the community and to support research in this field while motivating researchers in using OR to solve real problems in other fields of research.

\subsection{Success Factor}

Leimeister et al., (2006) identify 32 factors of success and rank them on the basis of importance to an organization and also validate these factors in the context of a real virtual organization. However, EWG ORD is not a profit making organization, so it adapts the success factors listed in Leimeister et al., (2002). In the following analysis, we use the adapted ranking scheme without differentiating the group population by sex, because EWG ORD is not a service based organization that offers services based on gender. Some of the adapted success factors are listed below:

- Sensitive handling of member data:

We only use the data to send emails that are informative about the community activities. EWG ORD does not use the data for commercial use.

- Stability and Fast reaction time of the website:

Changes on the web site are incorporated within 24 to 48 hours, because EWG ORD needs to manage different time zones. The principal decisions and updates are made by members distributed in Asia, USA, Europe, and Latin America.

- Assistance for new members by experienced members and establishing codes of behavior:

EWG ORD members consist of a group of professionals who join in the group to exchange ideas and assist each other with their expertise in problem solving. Exchange of ideas and creation of platform to solve the problems through dialogue are the foundation stones for the EWG ORD. The basic communication used in exchange of ideas and interactions between the members is through emails. Also, web admin plays a vital role in these exchange and interactions through posting in the website. EWG ORD has an implicit code of behavior for text or emails contemplated in the organizers consent which is channeled through the web admin.

- Offering up-to-date content and offering high-quality content:

EWG ORD offers links to national and international congress, workshop and events, and information shared in the workshops / conferences through reports. An ongoing proposal in the working group is to make a repository with the talks of past presentations at EWG ORD events, and also to publish emails of authors or researchers who wish to share their study in order to educate new generation researchers and students.

- Encouraging interaction between members, evolution of the community according to the ideas of its members, building trust among the members, arranging regular events and supporting the community by regular realworld meetings:

EWG ORD is actively involved in organizing / coorganizing workshops or streams on operational research for development in EURO 2006, EURO 2007, EURO 2008, IFORS 2008 and EURO 2009. For 2010, EWG ORD organized a workshop on operational research for development in EURO 2010 and ALIO INFORMS 2010, and involved in several national and international workshops and satellite events. This allows managing board members to interact with members of the community and also update the members. Also, this involvement attracts / motivates new members to join the group and it gives an invisible attachment to EWG ORD.

- Intuitive user guidance/usability:

This factor is explained in detail under the design of the web site factor.

- Reaching a high number of members within a short period of time, personalized page design of the community-site according to the preferences of its members:

EWG ORD does not provide a preference based web site.

- Integration of the members into the administration of the community and appreciation of contributions of the members by the operators:

These factors are the most difficult to implement, because paradoxically the response in terms of work is better from people from developed countries or with people who maintain relations with people from developed countries. The reason might be that developing countries are not so advanced in OR applications.

- About "Offering privileges or bonus programs to members" and "Establishing and supporting sub-groups within the community", members of EWG ORD look for funds to contribute to the organization of workshops and to give small scholarships to members from developing countries.

The factors "Sustaining neutrality when presenting and selecting offers", "Constant extension of offerings", "Price efficiency of offered products and services", "existence of an offline customer club as a starting advantage", "Increase of market transparency for community members", "Special treatment of loyal members", "Personalized product and service offers for community members" do not apply to EWG ORD, because the principal and primary priority is in academic and research order, not a commercial one. However, if EWG ORD were to get funds from enterprises in developing countries some of these factors could be discussed.

These factors offer a variety of aspects to consider empowering EWG ORD as a reference to look for information in Operational Research in developing countries and to build a bridge between researchers in developed and developing countries.

\subsection{Level of Trust}

In this dimension, EWG ORD gained adequate level of trust in terms of reputation (see Abdul-Rahman and Hailes 2000 
for reputation of web sites), because of the academic identities of its fellow researchers and members in the Managing and Advisory Boards. Globally recognized academicians generate trust for new and old members. However, there are some weak points; one such weak point is that EWG ORD doesn't have a platform to connect members of common research areas to interact with each other after a particular meeting or conference. The current implemented method is through emails that are shared across attendees of a particular conference / workshop.

Leimeister and Krcmar (2005) suggest two major factors, perceived competence and perceived goodwill that influence the development of trust. In the case of the first factor, EWG ORD does not have detailed information, but as stated above, reputation is a first step for it. For EWG ORD, the perceived competence published in special editions or portals does not apply, because EWG ORD does not receive funds and nor does it transfer funds from its members. Perceived goodwill can be experienced as the discovery of a cooperating partner's good intentions and can further lead to the development of interpersonal trust (Leimeister and Krcmar 2005). Regarding the set of trust-supporting components for the virtual community (Leimeister and Krcmar 2005), EWG ORD offers an adequate access rights concept and reasonable role models, but it is not evaluated yet, because users do not include their academic data, and for the moment, EWG ORD does not use trust seals.

The number of presentations illustrated in Figure 3 might be accepted an indicator for the level of trust in the community through their support to the workshops / conferences organ- ized. From 2006 to 2009 there is sharp increase in the number of contributions. The main reason in decline in the number of contributions in 2010 is the limited number of workshops organized.

\subsection{Virtual community management}

Leimeister and Krcmar (2005) describe that community management is usually associated with the activities of community development and the community. Strong and diligent management may play an active role in establishing trust between members and the community at the early/later stages of initiation of a virtual community.

The objective of virtual community management is without forcing power, through creating trust and considering risks while acting on incomplete information (Jansson, et al., 2007). EWG ORD is managed democratically by managing board members. These voluntary board members devote their time in organizing, educating, helping members of the community. The risks are related to the fact that EWG ORD does not have inscription of members, and it cannot change the members of managing boards permanently. Incomplete information is a constant factor affecting the capacity of bringing people together people in the workshop.

Figure 4 illustrates community management through organizing streams in several international and national conferences. It also indicates the success EWG ORD achieved in a short span of time and its impact on the community. There

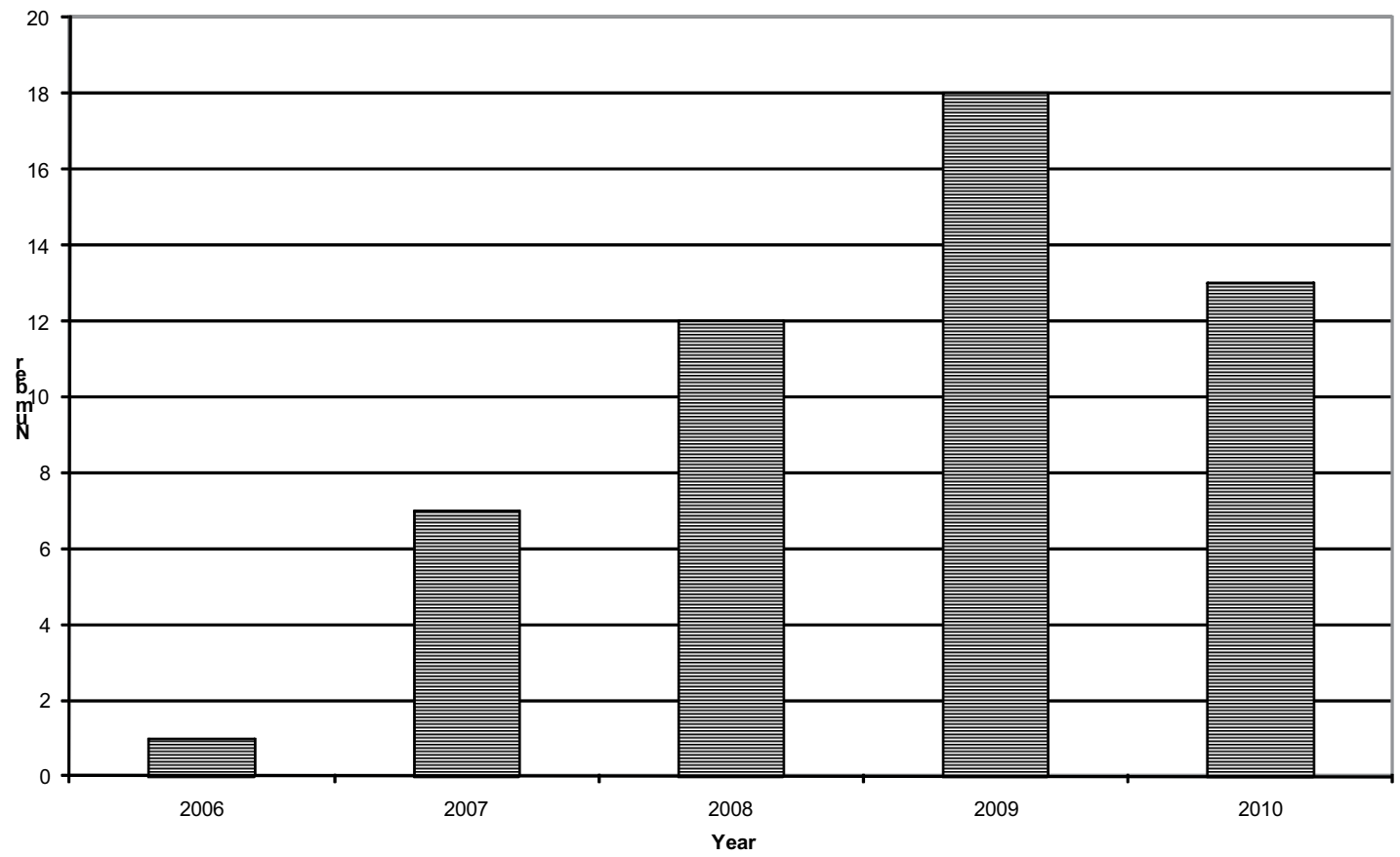

Figure 4: Distribution of total number of streams organized over the years 
is a steady increase in the number of streams organized every year except for the year 2010.

\subsection{Contents of the virtual community}

This dimension is not very well studied in the literature in the context of nonprofit virtual organizations. In the context of EWG ORD, the contents are mainly based on the goals and objectives of the working group. The main objective of this working group is to create a knowledge repository of real-time problems/case studies and applications of operational research that are solved in developing countries. EWG ORD also creates a platform to point out and exchange the problems that need to be addressed and solved in developing nations. As this virtual community does not receive any kind of membership fees from members and from EURO, its contents are more unbiased.

In summary, EURO ORD website is very specific form of social networking website. In case EURO ORD, website offers a platform for people to communicate and exchange ideas through emails, workshops, conferences and meetings. Here the website is facilitator which helps this networking possible. The specific topics discussed in this forum are application, methods to solve real-time problems in developing countries. These exchanges of ideas, so on excel the human capabilities in solving problem in more effective way. One of the main goals of any social networking website is to exchange views, ideas, and communicate about recent happening. EURO ORD serves all these goals without any doubt.

\section{Conclusions}

Nowadays, virtual organizations are a very popular and efficient tool to form a community of people with similar interests or ideas. In this paper, we present such a successful implementation of a non-profit research virtual organization, EWG ORD, which has evolved from common research interests. Here, we attempt to identify and analyze the six dimensions of virtual organizations in the context of the EWG ORD. The main strengths of this organization are its members and its managing board members and advisory board. EWG ORD successfully understands the needs of the community and creates a good level of trust. The level of trust, sense of belonging, and its management are illustrated by the participation of members the working group's conference streams.

A similar analysis can be conducted for understanding working groups not only under EURO but also under other international bodies. Such analysis also helps to generate ideas for building new working groups in the future.

\section{Acknowledgments}

The authors thank Mrs. Marthi Harmse, Mrs. Claudia Rave, Dr. Honora Smith, Prof. Theo Stewart, Prof. Leroy White, Dr. Elise del Rosario, Dra. Begoña Vitoriano Villanueva, Prof. Alexis Tsoukias and Mr. Hans Ittman for their great contributions and support to the working group. We wish to thank all our members and funding organizations, EURO and IFORS, for their generous financial support and help which made this dream come true.

\section{References}

Abdul-Rahman, A. \& Hailes, S. (2000). Supporting Trust in Virtual Communities. HICSS 00 : Proceedings of the $33^{\text {rd }}$ Hawaii International Conference on System Sciences, Volume 6. Publisher: IEEE Computer Society.

Bashiri, M. \& Mohtajeb, H. (2010). Distribution Centers Location decisions based on Analytical Network Process. EURO ORD Workshop on "OR for Developing Countries - Young Researchers and PhD Symposium", Lisbon July 10 2010. http://web.ing.puc.cl/ fcrespo/eurofdv/Lisbonconference/.

Blanchard, A. L. \& Markus, M. L. (2002). Sense of Virtual Community - Maintaining the Experience of Belonging. Proceedings of the $35^{\text {th }}$ Annual Hawaii International Conference on System Sciences (HICSS-35'02), USA.

Cochran, J. J. (2010). Working on Problems Faced by Developing Nations: Stories from the Front Line. EURO ORD Workshop on "OR for Developing Countries - Young Researchers and PhD Symposium", Lisbon July $10^{\text {th }}$, 2010. http://web.ing.puc. $\mathrm{cl} /$ fcrespo/eurofdv/Lisbonconference/.

ESIXXII (2004). The EURO Summer Institute ESI XXII, 2004, July 9-25, Ankara, Turkey, Retrieved January 10, 2012, from http:// www.iam.metu.edu.tr/esi04/.

EURO (2010). Association of European Operational Research Societies, Retrieved January 10, 2012, from http://www.euroonline.org/.

EWG ORD (2010). EWG ORD-Operational Research for Development Working Group of EURO, Retrieved January, 10, 2012, from http://web.ing.puc.cl/ fcrespo/eurofdv/.

INFORMS (2010). Institute for Operations Research and the Management Sciences, retrieved June 1, 2012, from http:// www.informs.org/

Jansson, K., Karvonen, I., Ollus, M., Salkari, I., Negretto, U., Klen, A. \& Paganelli, P. (2007). Virtual Organizations Management. In Encyclopedia of Networked and Virtual Organizations, Goran D. Putnik and Maria Manuela Cunha (Eds.), Hershey: Information Science Reference (an imprint of IGI Global), pp.1827-1833.

Kljajić Borštnar, M. (2012). Towards understanding collaborative learning in the social media environment, Organizacija, 45(3), 100-107, http://dx.doi.org/10.2478/v10051-012-0010-8

Leimeister, J. M. \& Krcmar, H. (2005). Evaluation of a systematic design for a virtual patient community. Journal of Computer-Mediated Communication, 10(4), article 6, http:// dx.doi.org/10.1111\%2Fj.1083-6101.2005.tb00269.x

Leimeister, J. M., Sidiras, P. \& Krcmar, H. (2006). Exploring Success Factors of Virtual Communities: The Perspectives of Members and Operators. Journal of Organizational Computing \& Electronic Commerce (JoCEC), 16 (3\&4), 279-298, http:// dx.doi.org/10.1080\%2F10919392.2006.9681204

Luna-Reyes, L.F., Black, L.J., Creswell, A.M., Pardo, T.A. (2008). Knowledge sharing and trust in collaborative requirements analysis, System Dynamics Review, 24, 265-297, http://dx.doi. org/10.1002\%2Fsdr.404

Rave, C. C. (2010). DSS for urban occupation patterns analysis, with social actors behavior and perception dynamics considerations. EURO ORD Workshop on "OR for Developing Countries Young Researchers and PhD Symposium", Lisbon July $10^{\text {th }}$, 2010. http://web.ing.puc.cl/ fcrespo/eurofdv/Lisbonconference/ 
Rheingold, H. (2000). The Virtual Community: Homesteading on the Electronic Frontier. London: MIT Press.

Rodgers, S. \& Chen, Q. (2005). Internet community group participation: Psychosocial benefits for women with breast cancer. Journal of Computer-Mediated Communication, 10(4), article 5. http://jcmc.indiana.edu/vol10/issue4/rodgers.html

Rosario, E. D. \& Rosario, J. D. (2010). Small Steps Toward Development: Sharing Experiences and Lessons Learned. EURO ORD Workshop on "OR for Developing Countries Young Researchers and PhD Symposium", Lisbon July $10^{\text {th }}$, 2010. http://web.ing.puc.cl/ fcrespo/eurofdv/Lisbonconference/

Yuan, P. S., Matthew K. O. L. \& Shao, Y. L. (2000). Virtual Organizations: The Key Dimensions. Proceeding AIWORC ' 00 Proceedings of the Academia/Industry Working Conference on Research Challenges, IEEE Computer Society Washington, DC, USA.

Wamalwa, T. (2007). Internet technology and challenges of virtual communities. International Journal of Business Research, BNET Business Library, July 2007. http://findarticles.com/p/ articles/mi_6773/

Weber, G-W., Pedamallu , C.S., Ozdamar, L., Kropat, E. \& Akar, H. (2010). A System Dynamics Model to Study the Importance of Infrastructure Facilities on Quality of Primary Education. EURO ORD Workshop on "OR for Developing Countries - Young Researchers and PhD Symposium”, Lisbon July 10 ${ }^{\text {th }}, 2010$. http://web.ing.puc.cl/ fcrespo/eurofdv/Lisbonconference/

Zurada, J. M. (2009). Virtual Organizations in Engineering and Computational Intelligence Virtual Community. Plenary Presentation in VI IEEE Latin-American Summer School on Computational Intelligence and III IEEE Latin-American Summer School on Robotics (EVIC 2009), December 15-18, 2009.

Fernando A. Crespo has his B. Tech. (1999) in Mathematical Engineering and (2001) in Industrial Engineering from University of Chile and Doctor in Science (2010) from Catholic University of Chile in field of Industrial Engineering. Currently he is a docent at University of Valparaiso (Chile), Industrial Engineering School. His basic research interests are in Operational Research, Operation Management, applied statistics, time series, data mining, dynamic data mining and soft sensor.
Chandra Sekhar Pedamallu has his B.Tech. (1999) in Mechanical Engineering from Nagarjuna University, India, M.Tech. (2001) in Industrial Management from Indian Institute of Technology Madras, India and Ph.d (2007) from the Division of Systems Eng. and Mgmt., Nanyang Technological University, Singapore. He did his Postdoctoral research fellowship at New England Biolabs, Ipswich, USA. Currently, Dr. Pedamallu is working as Sr. Computational Biologist, Meyerson Lab, Dana-Farber Cancer Institute, Boston, MA and as Associated Researcher at Cancer program, The Broad Institute of MIT and Harvard, Cambridge, MA. Dr. Pedamallu's expertise is in the areas of Computing, System modeling and dynamics, Bioinformatics and Optimization.

Linet Özdamar has BSc., MSc. and PhD. degrees from the Department of Industrial Engineering, Bogazici University, Istanbul, Turkey. Dr. Özdamar has held various academic and administrative positions at Marmara University, Nanyang Technological University and Yeditepe University. Dr. Özdamar is on the Scientific Board of the EURO Project Management and Scheduling Work Group, and a member of the Turkish OR Society. Having published more than 70 articles in various fields such as project scheduling, hierarchical planning, constrained optimization and logistics, Dr. Özdamar has received an impressive number of citations to her work.

Gerhard-Wilhelm Weber serves at IAM, METU, Ankara. His research in on optimization and control, OR, financial mathematics, on life, bio and human sciences, dynamical systems, data mining, inverse problems, environment and development. G.-W. Weber received his Diploma and Doctorate in mathematics, and economics / business administration, at RWTH Aachen, and his Habilitation at TU Darmstadt. He has affiliations at University of Siegen (Germany), University of Ballarat (Australia), University of Aveiro (Portugal), Malaysia University of Technology and University of North Sumatra (Indonesia). He has more than 200 publications, and is member in the Editorial Boards of ca. 15 journals. He is Advisor to EURO Conferences. 